\title{
FTIR spectroscopy structural analysis of the interaction between Lactobacillus kefir S-layers and metal ions
}

\author{
E. Gerbino ${ }^{\mathrm{a}, \mathrm{b}}$, P. Mobili ${ }^{\mathrm{a}, \mathrm{b}}$, E. Tymczyszyn ${ }^{\mathrm{a}}$, R. Fausto ${ }^{\mathrm{b}}$, A. Gómez-Zavaglia $^{\mathrm{a}, \mathrm{b}, *}$ \\ ${ }^{a}$ Centro de Investigación y Desarrollo en Criotecnología de Alimentos, La Plata RA-1900, Argentina \\ ${ }^{\mathrm{b}}$ Department of Chemistry, University of Coimbra, P-3004-535, Portugal
}

\section{A R T I C L E I N F O}

\section{Article history:}

Received 25 October 2010

Received in revised form 2 December 2010

Accepted 3 December 2010

Available online 14 December 2010

\section{Keywords:}

S-layer

Lactobacillus kefir

Metal ions

Secondary structure

Metal-protein coordination

\begin{abstract}
A B S T R A C T
FTIR spectroscopy was used to structurally characterize the interaction of S-layer proteins extracted from two strains of Lactobacillus kefir (the aggregating CIDCA 8348 and the non-aggregating JCM 5818) with metal ions $\left(\mathrm{Cd}^{+2}, \mathrm{Zn}^{+2}, \mathrm{~Pb}^{+2}\right.$ and $\left.\mathrm{Ni}^{+2}\right)$. The infrared spectra indicate that the metal/protein interaction occurs mainly through the carboxylate groups of the side chains of Asp and Glut residues, with some contribution of the $\mathrm{NH}$ groups belonging to the peptide backbone. The frequency separation between the $\nu \mathrm{COO}^{-}$anti-symmetric and symmetric stretching vibrations in the spectra of the S-layers in presence of the metal ions was found to be $c a .190 \mathrm{~cm}^{-1}$ for S-layer CIDCA 8348 and $c a .170 \mathrm{~cm}^{-1}$ for JCM 5818 , denoting an unidentate coordination in both cases. Changes in the secondary structures of the S-layers induced by the interaction with the metal ions were also noticed: a general trend to increase the amount of $\beta$-sheet structures and to reduce the amount of $\alpha$-helices was observed. These changes allow the proteins to adjust their structure to the presence of the metal ions at minimum energy expense, and accordingly, these adjustments were found to be more important for the bigger ions.
\end{abstract}

(c) 2010 Elsevier B.V. All rights reserved.

\section{Introduction}

In general, food and water represent the main sources of exposure to metals. Toxic metals are not degradable and tend to accumulate in the exposed organisms causing serious health effects. Therefore, their removal represents an important task for the care of both human and animal health and the environment. Bioremediation (the use of biological agents to remove or neutralize contaminants) is a very important tool for the removal of such toxics. In particular, the use of inactivated microorganisms as adsorbents (biosorption) has been suggested as an effective and economical way to remove heavy metals from water. Several genera of microorganisms have been used for such purposes [1-7]. Among lactic acid bacteria, different species of lactobacilli have been successfully used in the removal of lead and cadmium [8]. In spite of that, no bacterial structures have been conclusively assigned as responsible for the metal removal. To understand the molecular mechanisms involved in biosorption, a deep insight on the interaction of bacterial superficial structures with metals is necessary.

In several species of microorganisms, the S-layer represents the most outer structure covering the cell envelope, being attached to the peptidoglycan or the outer membrane by non-covalent bonds.

\footnotetext{
* Corresponding author at: Department of Chemistry, University of Coimbra, P-3004-535, Portugal.

E-mail address: angoza@qui.uc.pt (A. Gómez-Zavaglia).
}

Most of the S-layers are composed of protein monomers assembled in two-dimensional arrays with regularly arranged pores of identical size that enable the exchange of ions and small molecules between the living cells and their environment. The ability of S-layers to bind metal ions has attracted the attention due to the potential application in bioremediation and for the generation of metal nanoclusters that might receive different practical uses. For example, the uranium-mining waste pile isolate Bacillus sphaericus JG-A12 was found to be capable of selective and reversible binding of large amounts of different metals [4], functioning as a barrier for toxic heavy metal ions in the environment. S-layer extracts from the same microorganism, incubated in an $\mathrm{Au}^{3+}$ solution in the presence of reducing agents such as molecular $\mathrm{H}_{2}$, were able to form gold nanoparticles regularly distributed according to the pores of the protein lattice [9].

In spite of these evidences, the available information regarding the molecular basis of the S-layer/metal ions interaction and its consequences on the secondary structure of the S-layer proteins is still very scarce $[9,10]$. In contrast with many proteins that interact with metals through a low number of highly specific binding sites that are conformationally regulated by metal/protein interactions, S-layer proteins bear a high number of metal binding sites, each one exhibiting low specificity, thus being capable of binding a large variety of different metals $[4,10,11]$. In the interaction between $\mathrm{Pd}^{2+}$ and the S-layer of $B$. sphaericus JG-A12, a predominant chelation/bridging $\mathrm{Pd}^{2+}$ coordination to the side chain carboxylate groups of Asp and Glu residues, and a possible additional 
participation of nitrogen through side chains (Lys, Asn) rather than through the peptide backbone has been suggested [10].

In the present investigation, the interaction between the S-layers from two strains of Lactobacillus kefir and $\mathrm{Cd}^{+2}, \mathrm{Zn}^{+2}, \mathrm{~Pb}^{+2}$ and $\mathrm{Ni}^{+2}$ was addressed by FTIR spectroscopy. The characterization of the S-layer/metal interaction at a molecular level was undertaken and the impact of this interaction on the secondary structure of the S-layer proteins was evaluated.

\section{Materials and methods}

\subsection{Bacterial strains and growth conditions}

Two strains of $L$. kefir, JCM 5818 and CIDCA 8348, were used in this work. They were cultured in de Man, Rogosa and Sharpe (MRS) broth [12] (Biokar Diagnostics, Beauvais, France) at $30^{\circ} \mathrm{C}$ for $48 \mathrm{~h}$. Microorganisms were harvested and washed twice with milli $\mathrm{Q}$ water and the pellets obtained were suspended in $1 \mathrm{~mL}$ of $\mathrm{Pb}\left(\mathrm{NO}_{3}\right)_{2}$, $\mathrm{Cd}\left(\mathrm{NO}_{3}\right)_{2}, \mathrm{Ni}\left(\mathrm{NO}_{3}\right)_{2} \cdot 6 \mathrm{H}_{2} \mathrm{O}$ or $\mathrm{Zn}\left(\mathrm{NO}_{3}\right)_{2} \cdot 6 \mathrm{H}_{2} \mathrm{O} 0.3 \mathrm{mM}$ solution. Microorganisms non-treated with metal ions were used as controls. The suspensions were further incubated for $24 \mathrm{~h}$ at $30^{\circ} \mathrm{C}$. After that, they were centrifuged at $6600 \mathrm{~g}$ for $4 \mathrm{~min}$, and the pellets were used for transmission electronic microscopy determinations.

\subsection{Electron microscopy}

Samples for transmission electron microscopy (TEM) were prepared according to Vidgrén et al. [13]. Cells were fixed in $20 \mathrm{~g}$ glutaraldehyde/L (PBS buffer, $\mathrm{pH}=7.2$ ) for $15 \mathrm{~h}$, at room temperature. Fixed cells were collected by centrifugation and washed three times with phosphate buffer. All samples were post-fixed with phosphate-buffered $10 \mathrm{~g}$ osmium tetroxide/L and dehydrated for $2 \mathrm{~h}$. Samples were included in Epon 812 and sliced with a Sorvall MT 2B ultramicrotome. A JEOL 1200-EXII transmission electron microscope (Jeol Ltd., Japan) was operated at $85 \mathrm{kV}$.

\subsection{S-layer proteins preparation}

Bacterial cells were harvested at stationary phase, collected by centrifugation $\left(10,000 \mathrm{~g}\right.$ at $10^{\circ} \mathrm{C}$ for $\left.10 \mathrm{~min}\right)$, washed twice with $\mathrm{PBS}(\mathrm{pH}=7)$, and resuspended to an $\mathrm{OD}_{550 \mathrm{~nm}}$ of 10 in the same buffer. Cells were mixed with $5 \mathrm{M} \mathrm{LiCl}$ (J.T. Baker, Mallinckrodt Baker S.A., Mexico) in a proportion of $4 \mathrm{~mL}$ of solution per $\mathrm{mL}$ of bacterial suspension. The mixture was incubated in a shaking incubator (Environ Shaker, Lab-line Instruments Inc., Melrose Park, IL, USA) at 200 rpm and $37^{\circ} \mathrm{C}$ for $60 \mathrm{~min}$ to extract non-covalently bound proteins. Then, the mixture was centrifuged $\left(12,000 \mathrm{~g}\right.$ at $10^{\circ} \mathrm{C}$ for $\left.15 \mathrm{~min}\right)$. The supernatant containing the S-layer protein was concentrated by ultrafiltration in an Amicon stirred cell 8050 (Millipore Corporation, US) equipped with a regenerated cellulose membrane (Ultracell PLGC04310, MWCO 10,000, Millipore Corporation, US), and dialyzed against bidistilled water at $4{ }^{\circ} \mathrm{C}$ for $24 \mathrm{~h}$ using a cellulose membrane (SpectraPor membrane tube, MWCO 6000-8000, Spectrum Medical Industries, California, US). Taking advantage of the capacity of the S-layers to aggregate in the absence of chaotropic agents, the dialyzed extracts were centrifuged $4 \mathrm{~min}$ at $6600 \mathrm{~g}$ and the pellets were then suspended in $1 \mathrm{~mL}$ of $\mathrm{Pb}\left(\mathrm{NO}_{3}\right)_{2}, \mathrm{Cd}\left(\mathrm{NO}_{3}\right)_{2}, \mathrm{Ni}\left(\mathrm{NO}_{3}\right)_{2} \cdot 6 \mathrm{H}_{2} \mathrm{O}$ or $\mathrm{Zn}\left(\mathrm{NO}_{3}\right)_{2} \cdot 6 \mathrm{H}_{2} \mathrm{O} 0.3 \mathrm{mM}$ solution. S-layers non-treated with metal ions were used as controls. The suspensions were further incubated for $24 \mathrm{~h}$ at $30^{\circ} \mathrm{C}$. After that, they were centrifuged at $6600 \mathrm{~g}$ for $4 \mathrm{~min}$ and the pellets were used for the FTIR determinations.

\subsection{FTIR spectroscopy}

Thirty microliter of the S-layer pellets were put on a $\mathrm{CaF}_{2}$ window and further dried at $45{ }^{\circ} \mathrm{C}$ for $15 \mathrm{~min}$ to get a transparent film, which was directly used for FTIR experiments. The FTIR spectra of the S-layers were also recorded on $\mathrm{KBr}$ pellets to check for eventual effects of adsorption and the results obtained were found to be similar to those obtained in $\mathrm{CaF}_{2}$ (though of general worst quality, due to degradation of the optical material), indicating that adsorption, if taking place, is negligible. Note also that in the present study we are mostly interested in the differences observed in the spectra in the presence of the metals selected for the analysis, and, because the spectra of the proteins in the absence of these metals were systematically used as controls, possible undesired effects such as those due to an eventual adsorption were eliminated from the spectra analysis.

FTIR spectra were recorded in the $4000-500 \mathrm{~cm}^{-1}$ range in transmission mode in a system continuously purged under dry nitrogen in order to eliminate spectral contributions of atmospheric water vapor and $\mathrm{CO}_{2}$. The IR spectra collected at room temperature were obtained co-adding 128 scans with $4 \mathrm{~cm}^{-1}$ spectral resolution. All spectra were recorded in a BOMEM MB40 spectrometer (ABB Ltd., Zurich) with a $\mathrm{Zn} /$ Se beam splitter and a DTGS detector.

\subsection{Data analysis of FTIR spectra}

The recorded infrared spectra were analyzed using the OMNIC suit of programs (Nicolet Instrument Co., Madison, WI). Whenever necessary, residual contributions due to atmospheric water vapor and $\mathrm{CO}_{2}$ were eliminated by subtraction of the corresponding spectra from the registered samples' spectra. The resultant spectra were smoothed with a seven-point $\left(13 \mathrm{~cm}^{-1}\right)$ Savitzky-Golay function.

Inverted second derivative spectra were used to estimate the number and position of individual elements composing Amide I band (1600-1720 $\mathrm{cm}^{-1}$ ), and this information was taken into account to fit Amide I bands in protein spectra with Gaussian band profiles, using the program OMNIC (Nicolet Instrument Co., USA).

The assignment of protein secondary structures to the principal Amide I frequencies was as previously described in literature [14-17].

\section{Results and discussion}

According to previous studies carried out in our group, L. kefir strains have different surface properties. Among them, aggregation ability is perhaps one of the most important differential characteristic among strains, because of its putative role in some bacterial properties, such as adhesion to intestinal cells, biofilm formation, and pathogen inhibition [18-20]. Two L. kefir strains, CIDCA 8348 and JCM 5818, were here selected to investigate the bacteria/metal interaction. Considering that biosorption involves bacterial superficial molecules and that the structure of these molecules ultimately determines the aggregation properties of the whole microorganisms, the selection of these two strains has been made on the basis of their differential pattern of superficial properties (aggregation and co-aggregation abilities) $[18,20]$ (Table 1 ) and recognition by antibodies [23]. In these strains, S-layer represents the most outer structure covering the cell envelope and occupies ca. $90 \%$ of the outer surface [21]. Therefore, the interaction between the metal ions and the bacteria must essentially involve the S-layer.

Transmission electron micrographs of the two selected $L$. kefir strains before and after the treatment with metal ions clearly showed the presence of deposited metal on the bacterial S-layer surface. Fig. 1 shows the images obtained using lead ion. Similar results were observed after treatment with the other metal ions used in this work (not shown). This observation reinforced the interest in studying the interaction between the metal ions and the S-layer under well-controlled conditions. Therefore, purified S-layers from 
Table 1

Differential properties of L. kefir CIDCA 8348 and L. kefir JCM 5818.

\begin{tabular}{|c|c|c|c|c|c|c|}
\hline Strain & $H(\%)$ & $A C_{\mathrm{t}}$ & $C C_{\mathrm{t}}$ & $H_{\mathrm{t}}$ & S-layer molecular weight ( $\mathrm{kDa})$ & \%Adh \\
\hline L. kefir CIDCA 8348 & $83.0 \pm 1.0$ & $40.0 \pm 5.0$ & $23.1 \pm 9.8$ & + & $66 \pm 1$ & $4.5 \pm 1.3$ \\
\hline L. kefir JCM 5818 & $80.0 \pm 5.0$ & 0 & 0 & - & $69 \pm 1$ & ND \\
\hline
\end{tabular}

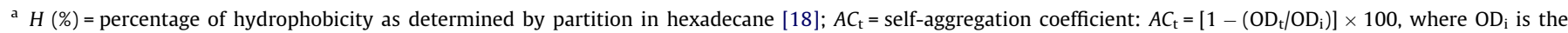

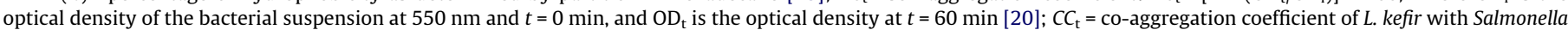

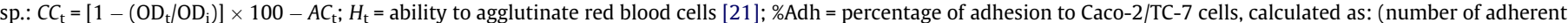
lactobacilli/number of lactobacilli added to the well) $\times 100$ [22]; ND, not determined.

\section{L. kefir CIDCA 8348}

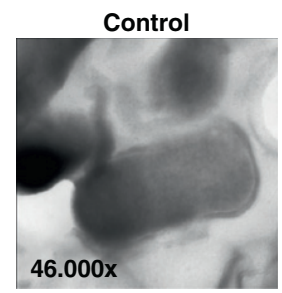

A

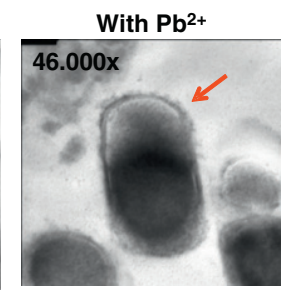

B
L. kefir JCM 5818

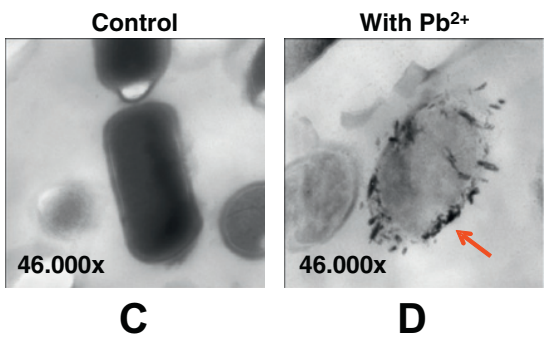

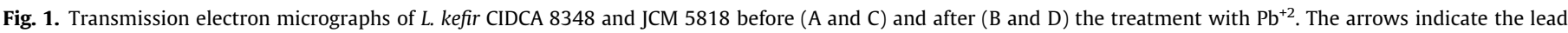

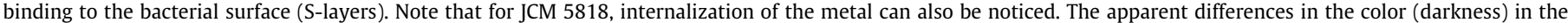
pictures are just artifacts of different illumination conditions.

L. kefir strains CIDCA 8348 and JCM 5818, were exposed to metal ions $\left(\mathrm{Cd}^{+2}, \mathrm{Zn}^{+2}, \mathrm{~Pb}^{+2}\right.$ and $\left.\mathrm{Ni}^{+2}\right)$ and analyzed by FTIR spectroscopy.

Fig. 2 shows the FTIR spectra obtained for the S-layers of $L$. kefir CIDCA 8348 and JCM 5818 before and after the treatment with the different metals. All spectra fit a typical infrared protein profile. In the $1800-1300 \mathrm{~cm}^{-1}$ region, amide I and amide II bands appear as the most prominent features. These bands correspond to collective vibrations of the peptide-chain backbone. The amide I band $\left(1700-1600 \mathrm{~cm}^{-1}\right)$ results essentially from the collective $\mathrm{C}=\mathrm{O}$ stretching vibration of the protein chain with a small contribution of the in-plane $\delta \mathrm{NH}$ bending mode of the peptide bond. This vibration is particularly sensitive to the secondary structure of a protein, and a detailed analysis of the observed amide I band profiles of the spectra shown in Fig. 2 will be presented later on in this paper to evaluate the effect of metal binding on the secondary structure of the S-layer proteins. The amide II band $\left(1580-1480 \mathrm{~cm}^{-1}\right)$ corresponds to a combination of the in-plane $\delta \mathrm{NH}$ bending mode with the stretching of the $\mathrm{C}-\mathrm{N}$ peptide bond. Another combination of these two vibrations gives rise to the amide III band, which is usually less intense than both the amide I and amide II bands and is observed in the $1300-1230 \mathrm{~cm}^{-1}$ range. The anti-symmetric stretching vibration of the carboxylates' side groups of Asp and Glu residues, $v \mathrm{COO}^{-}$ as., is known to give rise to a band in the high frequency wing of the amide II band, in the region $1580-1560 \mathrm{~cm}^{-1}[10,24]$. On the other hand, the symmetric stretching vibration of the same groups, $v \mathrm{COO}^{-}$ s., gives rise to the feature observed at $1430-1360 \mathrm{~cm}^{-1}$. Finally, the band appearing in the $1480-1430 \mathrm{~cm}^{-1}$ range is mainly due to $\delta \mathrm{CH}$ bending vibrations of the peptide-chain. Being very little affected by both direct metal binding effects and indirect metal binding effects due to changes in the secondary structure of the protein, this latter band is a good internal reference for quantitative measurements. The complete list of frequencies of the absorptions maxima, observed in the $1800-1300 \mathrm{~cm}^{-1}$ range, for the different systems studied and their corresponding assignments are given in Table 2.

\subsection{Coordination of the metal ions to L. kefir CIDCA 8348 and JCM 5818 S-layers}

The changes in the IR spectra of the S-layer occurring upon metal binding are better noticed in the data presented in Figs. 3 and 4, where difference spectra resulting from subtracting the spectrum of the native S-layer (control) to those of the metal-bound S-layer are shown. The spectral subtractions were performed after normalization of the spectra by the intensity of the $\delta \mathrm{CH}$ bending internal standard band at $1480-1430 \mathrm{~cm}^{-1}$.

In the case of the S-layer of the aggregating L. kefir CIDCA 8348 strain (Fig. 3), the pattern of the difference spectra is identical for all metals. In regard to the changes induced by the metal binding in the vibrational frequencies, there are two noticeable shifts: (i) the frequency corresponding to the maximum of the band due to the $v \mathrm{COO}^{-} \mathrm{s}$. vibrational mode decreases from $\mathrm{ca} .1407 \mathrm{~cm}^{-1}$ to $\sim 1380 \mathrm{~cm}^{-1}$ and (ii) the amide II band maximum shifts from $1535 \mathrm{~cm}^{-1}$ to $\sim 1495 \mathrm{~cm}^{-1}$. These frequency shifts are, naturally, accompanied by a decrease of the intensity in the spectral position of the $v \mathrm{COO}^{-} \mathrm{s}$. and amide II bands in the non-bound S-layer (see Fig. 3). Very interestingly, in the difference spectra, the band due to $\nu \mathrm{COO}^{-}$as. Asp and Glu side chain carboxylates' vibration can be clearly observed, with maximum at $c a .1575 \mathrm{~cm}^{-1}$. The observed changes in the amide I band, mostly an intensity reduction and contour modification, indicate that metal binding affects the secondary structure of the S-layer proteins. We will turn to this point later on.

The first conclusion that can be extracted from the data described is that the interaction S-layer/metals mainly occurs through the coordination of metals to the side chain carboxylates of the Asp and Glu residues. Extensive infrared studies on the relationship between the $v \mathrm{COO}^{-}$stretching frequencies and the coordination types have been performed [24-29]. Deacon and Phillips [25] have found a general tendency in the correlation between $\Delta v_{\text {as-s }}$ (frequency separation between the $v \mathrm{COO}^{-}$anti-symmetric and symmetric stretching vibrations) and the type of coordination between the carboxylate group and the metal ions. The frequency of the $v \mathrm{COO}^{-}$as. stretching of unidentate species is higher than that of the ionic (metal-free) species, which in turn is higher than that of bidentate species. The opposite behavior occurs in the case of the $v \mathrm{COO}^{-}$s. stretching vibration. As a result, the $\Delta v_{a s-s}$ values for unidentate, bridging, bidentate and ionic species are in the following order: $\Delta v_{a s-s}$ (unidentate) $>\Delta v_{a s-s}$ (ionic) $\sim \Delta v_{a s-s}$ (bridging) $>\Delta v_{a s-s}$ (bidentate), where $\Delta v_{a s-s}$ (ionic) is approximately $160-170 \mathrm{~cm}^{-1}$ [24-29]. In the case of the L. kefir CIDCA 8348 

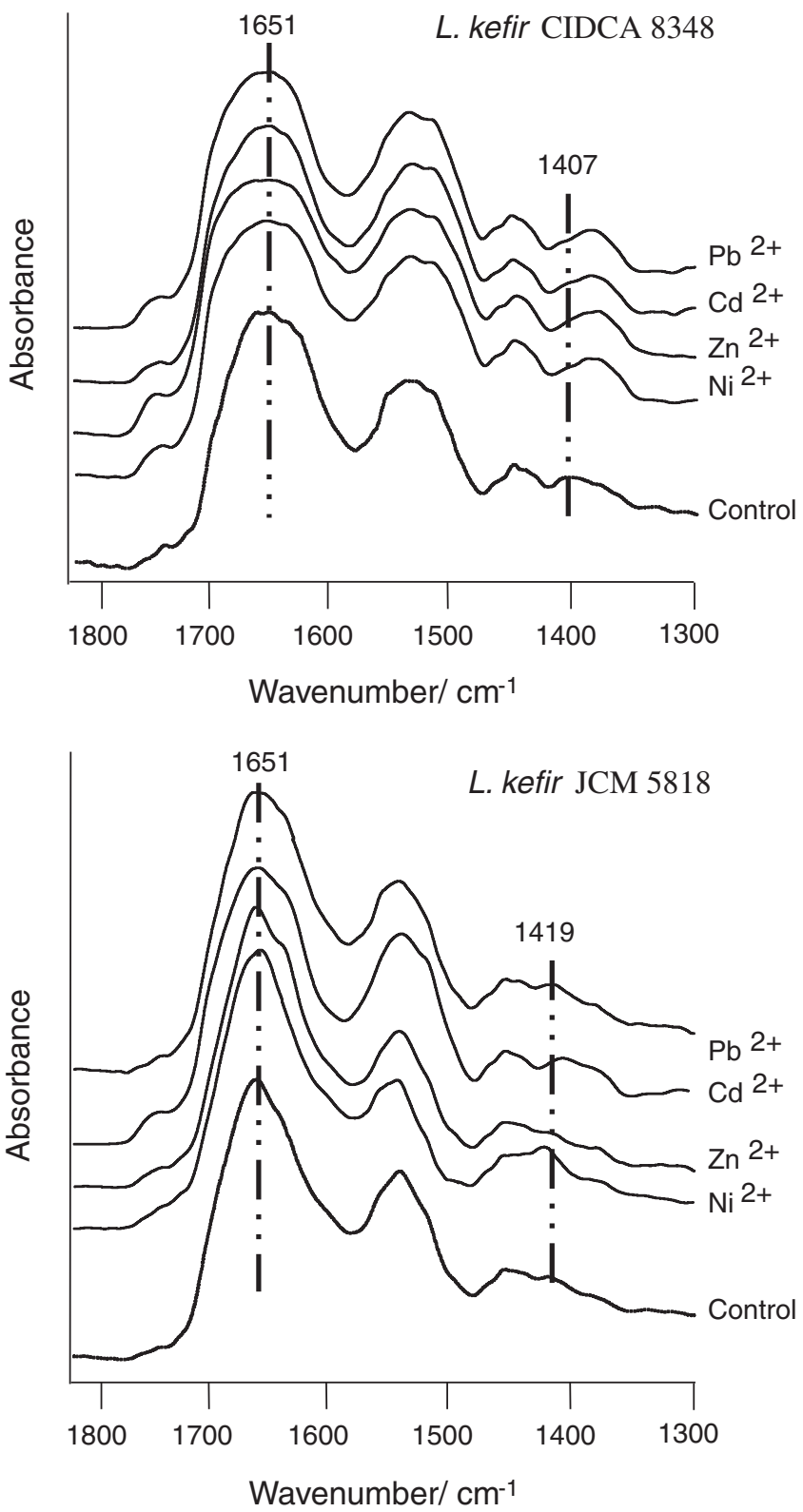

Fig. 2. FTIR spectra of S-layer proteins from L. kefir CIDCA 8348 and JCM 5818 incubated in the presence of: $\mathrm{Ni}^{2+}, \mathrm{Zn}^{2+}, \mathrm{Cd}^{2+}$ and $\mathrm{Pb}^{2+}$. Controls: S-layers nontreated with metals. The vertical dashed-dotted lines indicate the frequencies of the maximum of the bands ascribed to amide I and $v \mathrm{COO}^{-} \mathrm{s}$. in the control spectra.

S-layer/metal systems, $\Delta v_{a s-s}$ amounts to $c a .190 \mathrm{~cm}^{-1}$, suggesting that the coordination is predominantly unidentate. In this regard, the L. kefir S-layer shows a distinct behavior compared to that from

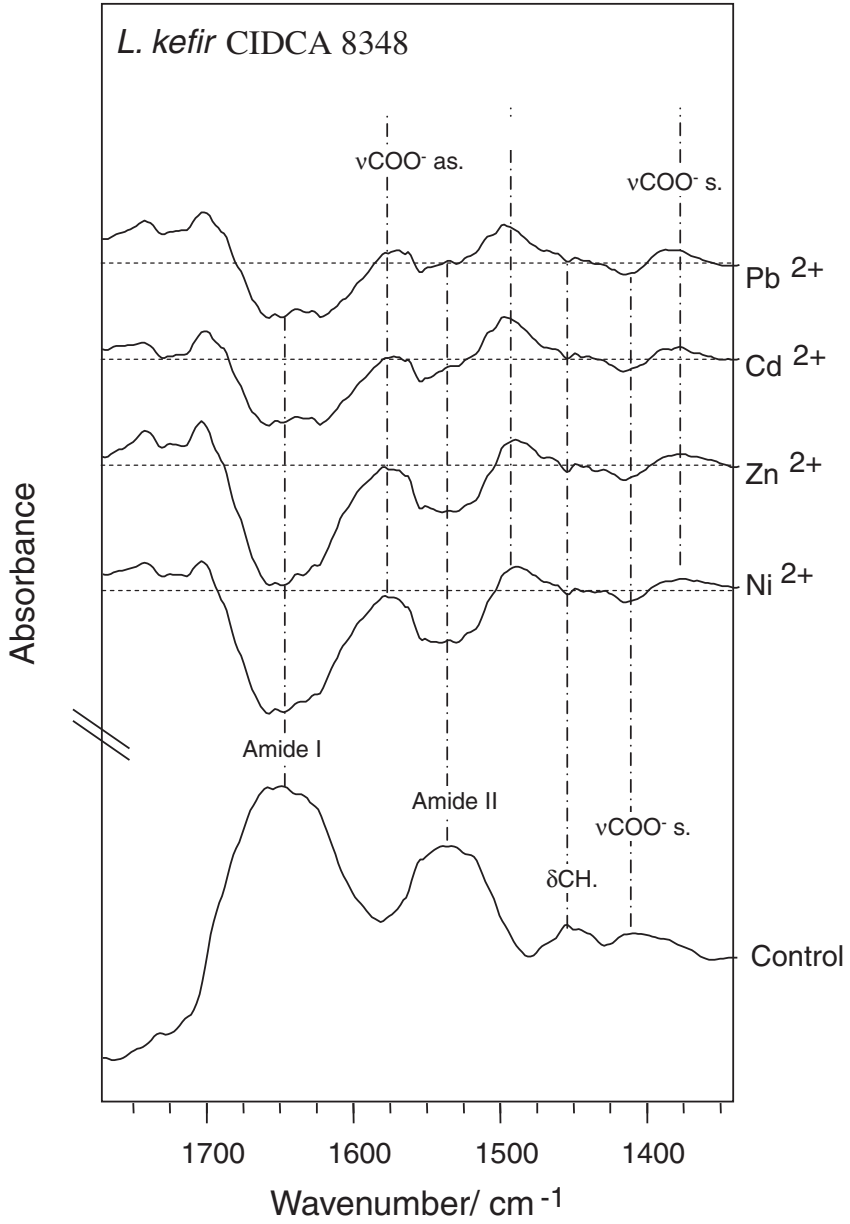

Fig. 3. FTIR difference spectra of S-layer proteins from strain L. kefir CIDCA 8348 induced by $\mathrm{Ni}^{2+}, \mathrm{Zn}^{2+}, \mathrm{Cd}^{2+}$ and $\mathrm{Pb}^{2+}$ binding. Control: FTIR spectrum of non-treated S-layer. In obtaining the difference spectra, the original spectra were normalized to the $\delta \mathrm{CH}$ internal standard. Dashed horizontal lines define the zero of the ordinate scale of the difference spectra. Vertical dashed-dotted lines indicate the frequencies of the maximum of the bands in the control spectrum or are "guide to the eyes" lines marked at approximately the average frequency maximum value of the bands ascribed to a given vibration in the spectra of the metal/protein systems (e.g., 1380 and $1575 \mathrm{~cm}^{-1}$ for the bands due to $v \mathrm{COO}^{-}$s. and $v \mathrm{COO}^{-}$as., respectively. Note that the band due to this latter mode is buried underneath those of amide I and II modes in the control spectrum).

B. sphaericus JG-A12, where coordination to $\mathrm{Pd}^{2+}$ was found to be predominantly bidentate [10]. Such results seem then to indicate that S-layer/metal interactions are strongly dependent on the structure of the non-treated S-layers, thus stressing the interest to extend this type of studies to S-layers from different composition.

Table 2

Experimental frequencies of the bands observed in the $1800-1300 \mathrm{~cm}^{-1}$ range for the different systems analyzed.

\begin{tabular}{|c|c|c|c|c|c|c|}
\hline S-layer & & Amide $\mathrm{I} / \mathrm{cm}^{-1}$ & $v \mathrm{COO}^{-}$as. $/ \mathrm{cm}^{-1}$ & Amide $\mathrm{II} / \mathrm{cm}^{-1}$ & $\delta \mathrm{CH} / \mathrm{cm}^{-1}$ & $v \mathrm{COO}^{-} \mathrm{s} . / \mathrm{cm}^{-1}$ \\
\hline \multirow[t]{5}{*}{ CIDCA 8348} & Control & 1651 & - & 1539 & 1454 & 1407 \\
\hline & $\mathrm{Ni}^{2+}$ & 1651 & 1577 & $1537 / 1493$ & 1454 & 1387 \\
\hline & $\mathrm{Zn}^{2+}$ & 1649 & 1575 & $1537 / 1494$ & 1454 & 1386 \\
\hline & $\mathrm{Cd}^{2+}$ & 1648 & 1562 & $1537 / 1496$ & 1454 & 1389 \\
\hline & $\mathrm{Pb}^{2+}$ & 1647 & 1562 & $1537 / 1496$ & 1454 & 1389 \\
\hline \multirow[t]{5}{*}{ JCM 5818} & Control & 1651 & - & 1540 & 1454 & 1419 \\
\hline & $\mathrm{Ni}^{2+}$ & 1651 & - & $1541 / 1496$ & 1454 & 1380 \\
\hline & $\mathrm{Zn}^{2+}$ & 1653 & - & $1542 / 1496$ & 1454 & 1380 \\
\hline & $\mathrm{Cd}^{2+}$ & 1654 & 1564 & $1538 / 1496$ & 1454 & 1386 \\
\hline & $\mathrm{Pb}^{2+}$ & 1654 & 1576 & $1542 / 1496$ & 1454 & 1382 \\
\hline
\end{tabular}




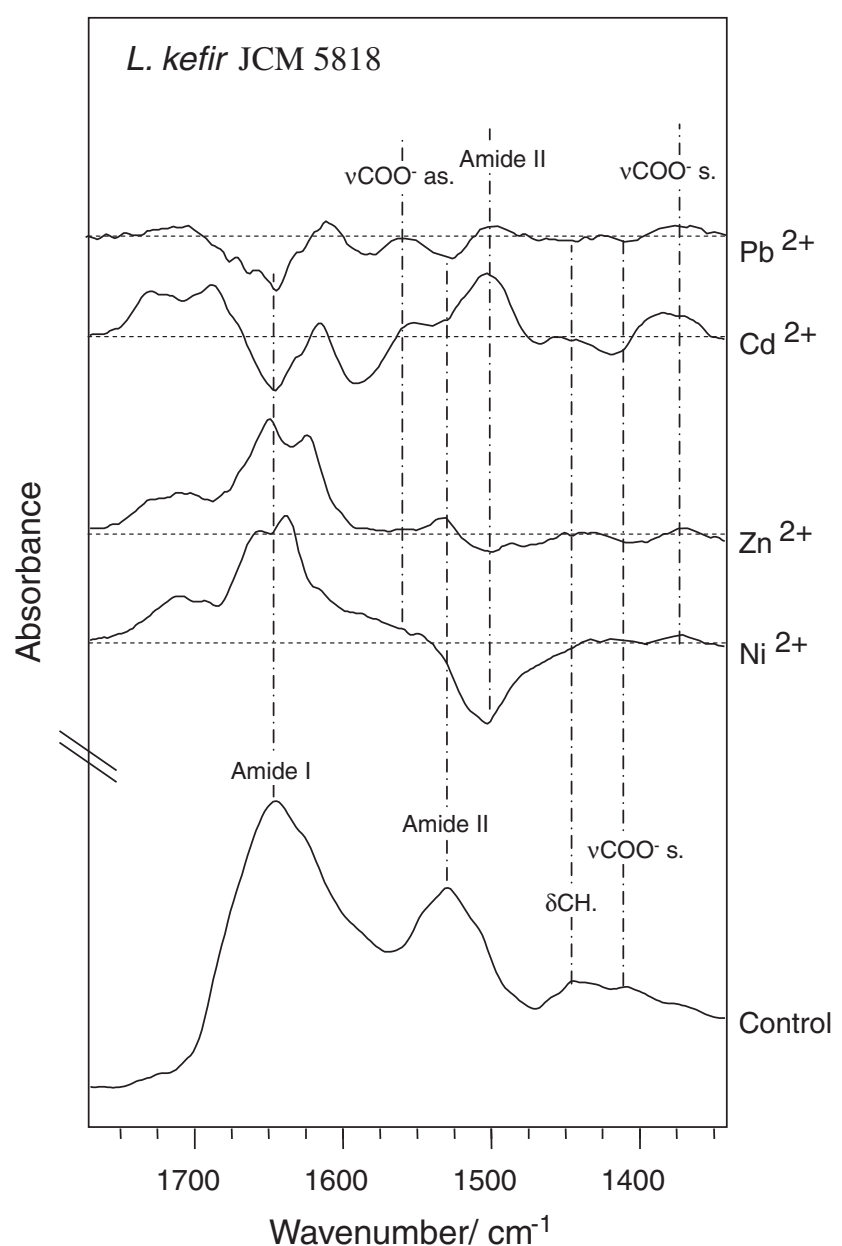

Fig. 4. FTIR difference spectra of S-layer proteins from strain L. kefir JCM 5818 induced by $\mathrm{Ni}^{2+}, \mathrm{Zn}^{2+}, \mathrm{Cd}^{2+}$ and $\mathrm{Pb}^{2+}$ binding. Control: FTIR spectrum of non-treated S-layer. In obtaining the difference spectra, the original spectra were normalized to the $\delta \mathrm{CH}$ internal standard. Dashed horizontal lines define the zero of the ordinate scale of the difference spectra. Vertical dashed-dotted lines indicate the frequencies of the maximum of the bands in the control spectrum or are "guide to the eyes" lines marked at approximately the average frequency maximum value of the bands ascribed to a given vibration in the spectra of the metal/protein systems (e.g., 1380 and $1575 \mathrm{~cm}^{-1}$ for the bands due to $v \mathrm{COO}^{-} \mathrm{s}$. and $v \mathrm{COO}^{-}$as., respectively. Note that the band due to this latter mode is buried underneath those of amide I and II modes in the control spectrum).

The changes observed in the L. kefir CIDCA 8348 S-layer amide II region upon metal binding do not follow the pattern previously found for B. sphaericus JG-A12 either [10]. In this latter case, no changes were observed in that region, and this fact was taken as an evidence of non-participation of the peptide backbone nitrogen atoms in the coordination to the metal ions. Instead, side-chain nitrogen atoms from mainly Lys and Asn residues of the B. sphaericus JG-A12 S-layer were considered to be involved in the additional coordination to the metal ions [10]. In the case of L. kefir CIDCA 8348 S-layer, however, the changes in the amide II band upon metal binding are important (Fig. 3), with a redshift of the band maximum of $c a .40 \mathrm{~cm}^{-1}$, which indicates that in this case the peptide backbone nitrogen atoms are playing an active role in the coordination to the metal.

For the S-layer of the non-aggregating $L$. kefir JCM 5818 strain (Fig. 4), the pattern of the difference spectra resulting from subtracting the spectrum of the native S-layer (control) to those of the metal-bound S-layer is not identical for all metals. The spectral changes induced by the bigger $\mathrm{Cd}^{2+}$ and $\mathrm{Pb}^{2+}$ metals follow the same trends as the above discussed for $L$. kefir CIDCA 8348, and can be interpreted in the same way. However, the spectral changes induced by the smaller $\mathrm{Ni}^{2+}$ and $\mathrm{Zn}^{2+}$ species follow a different pattern. In these cases: (i) the frequency of the maximum of the band due to the $v \mathrm{COO}^{-} \mathrm{s}$. mode also decreases from $c a .1419 \mathrm{~cm}^{-1}$ to $\sim 1380 \mathrm{~cm}^{-1}$, still suggesting a dominance of the unidentate coordination in these systems. In spite of that, the position of the $v \mathrm{COO}^{-}$as. mode could not be unequivocally determined, precluding a more definitive assignment of the unidentate coordination as the prevalent coordination type in these two cases; (ii) the amide II band exhibits an increase of intensity in its high frequency region and a decrease in the low frequency region. This is just the opposite trend with regard to that found for all the other cases studied in this work, and might indicate that these two (smaller) metal ions are able to penetrate more extensively inside the S-layer proteins of L. kefir JCM 5818 and perturb their local environment making it more hydrophobic, e.g., by replacing residual solvent molecules or redefining specific contacts involving the $\mathrm{NH}$ moieties of the peptide bonds [8] and (iii) the intensity changes observed in the amide I band were also of opposite signal compared to those found for the other systems investigated. Since this must be connected with changes in the secondary structure of the S-layer upon metal binding, we defer the interpretation of this result for later in this paper.

In conclusion, Glu and Asp carboxylate side chain groups were found to be the main interacting molecular fragments with the metal ions in both L. kefir CIDCA 8348 and JCM 5818 S-layers. This result is in agreement with previously obtained data for the interaction of $B$. sphaericus JG-A12 with $\mathrm{Pd}^{2+}[10]$. In addition, in both $L$. kefir S-layer proteins analyzed, the type of preferential carboxylate/metal ion coordination was determined to be unidentate and is complemented by interactions which also involve nitrogen atoms of the peptide linkage. Such findings contrast with those found for B. sphaericus $/ \mathrm{Pd}^{2+}$ system, where the preferential coordination was identified as predominantly bidentate with secondary coordinations involving Lys and Asn side-chain nitrogen atoms [10]. Among the two S-layer types investigated in this study, the S-layer from the aggregating strain L. kefir CIDCA 8348 is known to have a lower ability to bind metals than that of the non-aggregating JCM 5818 strain [30]. The number of available metal binding sites in this latter is larger and, according to the present results, the access of the smaller metal ions $\left(\mathrm{Ni}^{2+}\right.$ and $\left.\mathrm{Zn}^{2+}\right)$ to the interior of the proteins appear to be easier, leading to the observed differential behavior found for these metal ions in relation to the one observed for the other S-layer/metal interactions.

\subsection{Effect of metal binding on the secondary structures of L. kefir CIDCA 8348 and JCM5818 S-layer proteins}

As already mentioned, binding of metal ions to S-layer also produces changes in the secondary structure of the S-layer proteins.

Table 3

Secondary structure composition (\%) for S-layer proteins from L. kefir CIDCA 8348 and JCM 5818.

\begin{tabular}{|c|c|c|c|c|}
\hline \multirow[t]{2}{*}{ S-layer } & \multicolumn{4}{|c|}{ Secondary structure (\%) } \\
\hline & & $\alpha$-Helix & $\beta$-Sheet & Other $^{\mathrm{a}}$ \\
\hline \multirow[t]{5}{*}{ CIDCA 8348} & Control & 28.0 & 19.1 & 52.9 \\
\hline & $\mathrm{Ni}^{2+}$ & 10.8 & 23.8 & 65.4 \\
\hline & $\mathrm{Zn}^{2+}$ & 34.0 & 42.1 & 23.9 \\
\hline & $\mathrm{Cd}^{2+}$ & 23.9 & 45.8 & 30.3 \\
\hline & $\mathrm{Pb}^{2+}$ & 14.3 & 57.9 & 27.8 \\
\hline \multirow[t]{5}{*}{ JCM 5818} & Control & 36.0 & 15.3 & 48.7 \\
\hline & $\mathrm{Ni}^{2+}$ & 38.7 & 25.3 & 36.0 \\
\hline & $\mathrm{Zn}^{2+}$ & 29.9 & 30.2 & 39.9 \\
\hline & $\mathrm{Cd}^{2+}$ & 21.0 & 27.9 & 51.1 \\
\hline & $\mathrm{Pb}^{2+}$ & 13.7 & 21.9 & 64.4 \\
\hline
\end{tabular}

a Includes $\beta$-turns and non-ordered structures, as well as side chain vibrations. 
These changes are particularly evident in the alterations produced in the amide I spectral region upon binding.

Fig. S1 shows illustrative examples of the results corresponding to the curve-fitting procedure used to determine the relative contributions of the amide I band components. This process allowed us to obtain the composition of the secondary structure for all the investigated samples (S-layers of L. kefir CIDCA 8348 and JCM 5818 before and after the treatment with the different metal ions). Data for S-layer of L. kefir JCM 5818 and for this S-layer in presence of $\mathrm{Ni}^{2+}$ and $\mathrm{Cd}^{2+}$ are displayed in the figure. The whole set of obtained results are given in Table 3.

The interaction with metal ions produces noticeable changes in secondary structures of both S-layer proteins. In particular, it induces a general trend to increase the amount of $\beta$-sheet structures
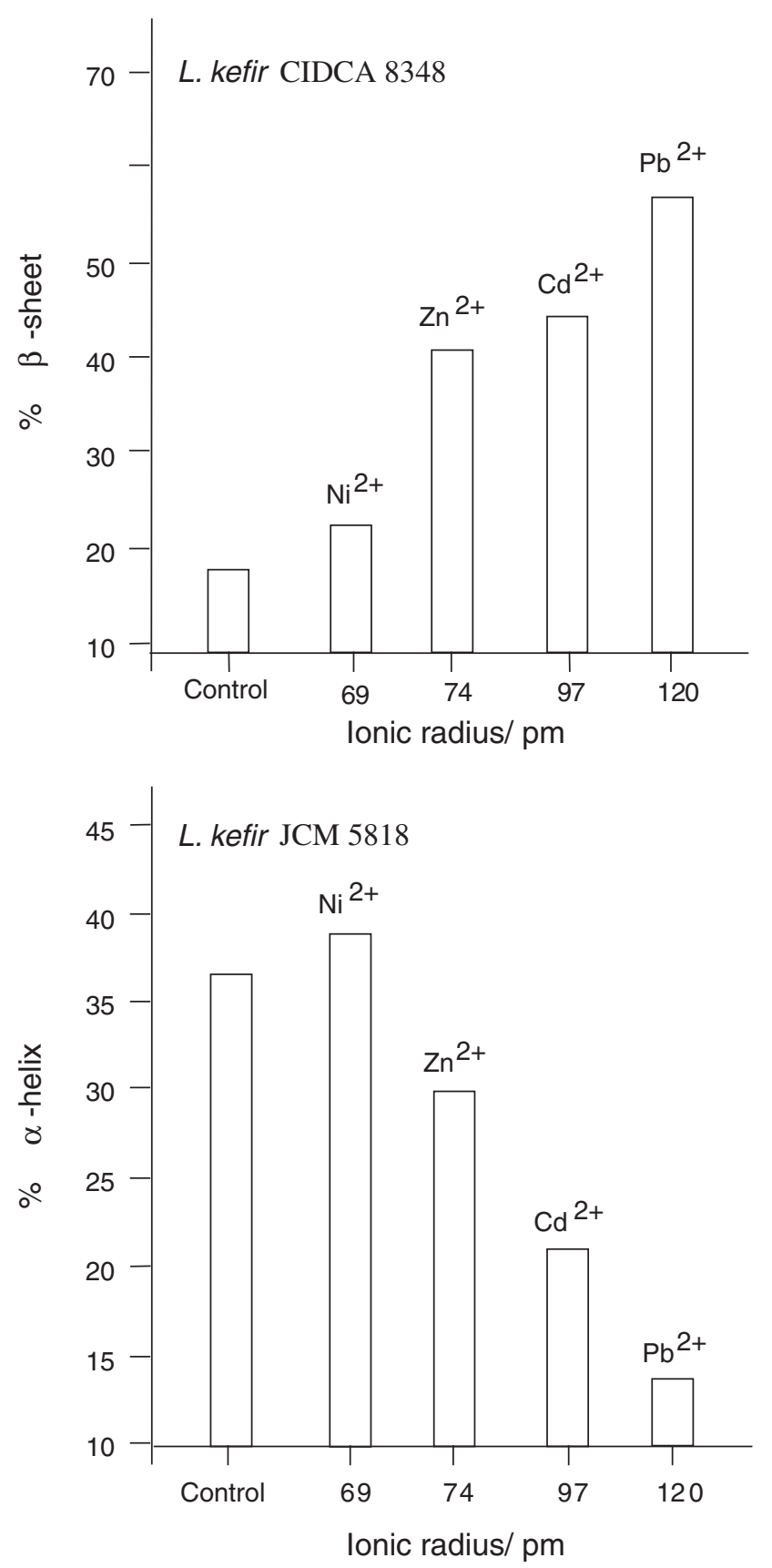

Fig. 5. Effect of the ionic radius of divalent metal ions $\left(\mathrm{Ni}^{2+}, \mathrm{Zn}^{2+}, \mathrm{Cd}^{2+}\right.$ and $\left.\mathrm{Pb}^{2+}\right)$ on the $\alpha$-helix and $\beta$-sheet secondary structures of S-layer proteins extracted from $L$. kefir strains CIDCA 8348 and JCM 5818. Controls: non-treated S-layers. and reduce the $\alpha$-helices. In addition, the observed decrease in the $\alpha$-helix contents for JCM 5818 and the increase of the $\beta$-sheet structures in CIDCA 8348 follow nearly linear relationships with the radius of the metal ions (Fig. 5). This indicates that bigger metal ions induce these proteins to change their composition from $\alpha$-helix to $\beta$-sheets in a greater extent. Interestingly, a correlation with the hydrated radii of the metal ions was not observed, indicating that the protein/metal interactions are strong enough to replace the water molecules that are eventually still present in the vicinity of the metal ions.

The decrease of $\alpha$-helix structures and increase in $\beta$-sheets contents has been frequently observed in different types of proteins under variations of $\mathrm{pH}$ [31], temperature [32], solvent composition [33], and under mechanical deformation as shown by experiment and simulation [34-37]. These structural changes lead to a significant increase in the protein's stiffness, strength, and energy dissipation capacity at deformation [38]. It looks then probable that the decrease in $\alpha$-helix structures and increase in $\beta$-sheets contents observed for the L. kefir JCM 5818 and CIDCA 8348 S-layer proteins upon metal binding is just the way the proteins found to adjust its structure to the presence of the metal ions at minimum energy expense. This interpretation also explains why the effects of metal binding upon the secondary structure of the proteins tend to be more pronounced for bigger ions.

\section{Conclusions}

The experiments reported in this paper allowed us to shed light on relevant molecular details of the interaction between the S-layers of two L. kefir strains and a series of divalent heavy metal ions. From the results obtained, the following main conclusions could be extracted:

(1) The observed deposition of heavy metals on the bacterial surface (Fig. 1) clearly demonstrated the relevance of the S-layer/metal ions interaction.

(2) The interaction S-layer/metal ion induces important changes in the structure of the S-layers, as observed by FTIR spectroscopy.

(3) In both studied S-layers, the protein/metal interaction occurs mainly through coordination with the side chain carboxylate groups of the Asp and Glu residues. This coordination is predominantly unidentate and is complemented by additional coordinations involving $\mathrm{NH}$ groups from the peptide backbone.

(4) In the case of the S-layer of L. kefir JCM 5818, the interaction with $\mathrm{Ni}^{2+}$ and $\mathrm{Zn}^{2+}$ does not seem to follow the same pattern as that corresponding to the interaction with $\mathrm{Cd}^{2+}$ and $\mathrm{Pb}^{2+}$ (or that found for the interaction between all studied metal ions and the S-layer of $L$. kefir CIDCA 8348). In fact, even if the interaction with $\mathrm{Ni}^{2+}$ and $\mathrm{Zn}^{2+}$ ions is, with all probability, also unidentate, the observed increase in the intensity of the amide I band upon binding of these metals to the S-layer of L. kefir JCM 5818 indicates that their smaller size allows them to penetrate more extensively inside the proteins and perturb their local environment, making it more hydrophobic.

(5) The interaction with metals also induces changes in the secondary structure of the S-layers. These changes were found to obey a general trend to increase the amount of $\beta$-sheet structures and reduce the $\alpha$-helices, which allows the proteins to adjust their structure to the presence of the metal ions at minimum energy expense [38]. Accordingly, as a trend, bigger ions were found to produce more significant changes in the secondary structure of the studied proteins. 
Finally, it must also be underlined that the primary structures of S-layer proteins are known to be extremely variable, even between strains belonging to the same species [39]. Due to this great diversity, the practical application of S-layers, e.g., in bioremediation, seems to require an analysis of the interaction S-layer/metal ion for each particular case. In this regard, due to its high sensitivity to any changes in environment of protein molecular groups, FTIR spectroscopy appears as an adequate choice to get an insight on the functional groups involved in the S-layer/metal interaction.

\section{Acknowledgements}

The authors are grateful to ANCPCyT (Projects PICT(2006)/ 00068) and PICT(2008)/145), the Portuguese Strategic Reference Framework (Project KEFIR-5376-QREN-SI\&DT - Co-Promoção), MinCyT and FCT (bilateral cooperation Grant FCT-MinCyT PO/09/ 18) and CYTED Program (Network 108RT0362) for financial support. AGZ, PM and EET are members of the Research Career CONICET, Argentina. EG is fellow of ANPCyT.

\section{Appendix A. Supplementary data}

Supplementary data associated with this article can be found, in the online version, at doi:10.1016/j.molstruc.2010.12.012.

\section{References}

[1] T. Barkay, J. Schaefe, Curr. Opin. Microbiol. 4 (2001) 318.

[2] T. Iwamoto, M. Nasu, Biosci. Bioeng. 92 (2001) 1.

[3] X.C. Kretschmer, G. Meitzner, J.L. Gardea-Torresdey, R. Webb, Appl. Environ. Microbiol. 70 (2004) 771

[4] S. Selenska-Pobell, P. Panak, V. Miteva, G. Bernhard, H. Nitsche, FEMS Microbiol. Ecol. 29 (1999) 59.

[5] S.S. Ahluwalia, D. Goyal, Bioresour. Technol. 98 (2007) 2243.

[6] M. Valls, V. de Lorenzo, FEMS Microbiol. Rev. 26 (2002) 327.

[7] J.E.B. Cayllahua, R.J. de Carvalho, M.L. Torem, Miner. Eng. 22 (2009) 1318.

[8] T. Halttunen, S. Salminen, R. Tahvonen, Int. J. Food Microbiol. 114 (2007) 30.

[9] M. Merroun, A. Rossberg, C. Hennig, A.C. Scheinost, S. Selenska-Pobell, Mater. Sci. Eng. C 27 (2007) 188
[10] K. Fahmy, M. Merroun, K. Pollmann, J. Raff, O. Savchuk, C. Hennig, S. SelenskaPobell, Biophys. J. 91 (2006) 996.

[11] K. Pollmann, J. Raff, M. Merroun, K. Fahmy, S. Selenska-Pobell, Biotechnol. Adv. 24 (2006) 58.

[12] J.C. de Man, M. Rogosa, M.E. Sharpe, J. Appl. Bacteriol. 23 (1960) 130.

[13] G. Vidgrén, I. Palva, R. Pakkanen, K. Lounatmaa, A. Palva, J. Bacteriol. 174 (1992) 7419.

[14] H.R. Costantino, K.G. Carrasquillo, R.A. Cordero, M. Mumenthaler, C.C. Hsu, K. Griebenow, J. Pharm. Sci. 87 (1998) 1412.

[15] A. Dong, P. Huang, W.S. Caughey, Biochem 29 (1990) 3303.

[16] H. Torii, M. Tasumi, in: H. Mantsch, D. Chapman (Eds.), Infrared Spectroscopy of Biomolecules, Wiley Liss Inc., 1996, pp. 1-18 (Chapter 1).

[17] P.O. Souillac, C.R. Middaugh, J.H. Rytting, Int. J. Pharm. 235 (2002) 207.

[18] P.F. Pérez, J. Minnaard, E.A. Disalvo, G.L. De Antoni, Appl. Environ. Microbiol. 64 (1998) 21

[19] B. Kos, J. Šuškovic, S. Vukovic, M. Šimpraga, J. Frece, S. Matošic, J. Appl. Microbiol. 94 (2003) 981.

[20] M.A. Golowczyc, P. Mobili, G.L. Garrote, A.G. Abraham, G.L. De Antoni, Int. J. Food Microbiol. 118 (2007) 264.

[21] G.L. Garrote, L. Delfederico, R. Bibiloni, A.G. Abraham, P.F. Pérez, L. Semorile G.L. De Antoni, J. Dair. Res. 71 (2004) 1.

[22] M.A. Golowczyc, Ph.D. Thesis. University of La Plata, Argentina, 2008.

[23] G.L. Garrote, M.A. Serradell, A.G. Abraham, M.C. Añon, C.A. Fossati, G.L. De Antoni, Food Agricult. Immunol. 16 (2005) 221.

[24] M. Nara, M. Tanokura, Biochem. Biophys. Res. Commun. 369 (2008) 225.

[25] G.B. Deacon, R.J. Phillips, Coord. Chem. Rev. 33 (1980) 227.

[26] K. Nakamoto, Infrared and Raman Spectra of Inorganic and Coordination Compounds Part B, fifth ed., Wiley, New York, 1997. pp. 57-62.

[27] J.E. Tackett, Appl. Spectrosc. (1989) 483.

[28] M.A. Mesubi, J. Mol. Struct. 81 (1982) 61.

[29] M.F. Ramos Moita, M.L.T.S. Duarte, R. Fausto, J. Chem. Soc. Faraday Trans. 90 (1994) 2953.

[30] A. Alves, Interacção entre Aminoácidos Simples e Proteínas de Camada-S do Lactobacillus kefir e Iões Metálicos, Graduation Thesis, Department of Chemistry, University of Coimbra, Coimbra, Portugal, 2010. (Chapter 2).

[31] T. Koga, K. Taguchi, Y. Kobuke, T. Kinoshita, M. Higuchi, Chem. Eur. J. 9 (2003) 1146.

[32] F. Ding, J.M. Borreguero, S.V. Buldyrey, H.E. Stanley, N.V. Dokholyan, Proteins: Struct. Funct. Genet. 53 (2003) 220.

[33] M. Meier, J. Seelig, J. Am. Chem. Soc. 130 (2008) 1017.

[34] J.S. Church, G.L. Corino, A.L. Woodhead, J. Mol. Struct. 440 (1998) 15

[35] L. Kreplak, J. Doucet, P. Dumas, F. Briki, Biophys. J. 87 (2004) 640

[36] D.S. Fudge, K.H. Gardner, V.T. Forsyth, C. Riekel, J.M. Gosline, Biophys. J. 85 (2003) 2015.

[37] L. Kreplak, H. Herrmann, U. Aebi, Biophys. J. 94 (2008) 2790.

[38] Z. Qin, M.J. Buehler, Phys. Rev. Lett. 104 (2010) 198304.

[39] S. Åvall-Jääskeläinen, A. Palva, FEMS Microbiol. Rev. 29 (2005) 511. 